\title{
Analysis of the Communication Effect of Mobile Internet Advertising
}

\author{
H.YU \\ School of Economics and Management, Communication University of China, Beijing, China \\ Y.F.ZHAO \\ College of business administration, Missouri State University, Springfield, Missouri, USA
}

\begin{abstract}
The data released by The Ministry of Industry and Information Technology shows that in the early 2014, the number of mobile Internet users has reached 838 million, while the proportion of mobile Internet advertising in the whole Chinese advertising market is only up to $1.5 \%$. The poor effect of advertising accounts for the small share of the advertising market. Therefore, how to enhance the communication effect of mobile Internet advertising is a problem needed to be solved urgently. This paper first presents the mobile Internet advertising communication effect is not ideal. Then after combining the available data, obtained specific causes, finally gives the advertising evaluation and billing methods for improve the advertising communication effect of mobile Internet.
\end{abstract}

KEYWORDS: Communication Effect; Mobile Internet; Advertising

\section{INTRODUCTION}

In recent years, as mobile Internet develops rapidly, the turnover of its advertising increases more than $90 \%$ per year. As the user scale continues to expand, business model of mobile Internet advertising has also been upgraded. And the problems in the process attract the attention of practitioners and scholars. The author combed through the relevant literature and found that the existing studies start mostly from the mobile Internet industry chain and talk about the status of the mobile Internet advertising business, features, difficulties and disadvantages, as well as strategies and recommendations while there are fewer researches on the effect of mobile Internet advertising. Advertising communication effectiveness is the impact of advertising on the aspects of audience's perception, memory, understanding, emotions, attitudes and behavior, and it depends on the comprehensive effect of advertising form and media choice. Despite the rapid development of mobile Internet, the total investment on advertising is far from expectation.

\section{THE ACTUAL SITUATION OF COMMUNICATION EFFECT OF MOBILE INTERNET ADVERTISING}

\subsection{Effective click rate is not high}

The Chinese e-commerce research report pointed out that the click rate of most mobile Internet advertising is less than $1 \%$, and the average click rate is $5 \%$. Meanwhile, Trademob survey shows that around $40 \%$ of the advertising clicks turn out to be wrong or fraudulent clicks. And the deception of advertiserfacing mobile advertising data is already an open secret. Advertising operators often fabricate a data which is impressive but not too much to attract advertisers. Therefore, it is reasonable that advertisers do not trust mobile Internet advertising, correspondingly unwilling to waste the cost of advertising in the mobile Internet.

\subsection{The market share is small; the target audience has its limitations}

Although the total amount of mobile Internet advertising growth for recent two consecutive years has reached more than $90 \%$, the market share of mobile Internet advertising still stays small. In the meanwhile, the mobile Internet advertising audience mainly aged from 15 to 30 years old who have low consuming capacity exactly. And the proportion of the 30-40year middle-aged population with high consuming capacity is less than $20 \%$. This situation leads directly to the limitations of mobile Internet advertising, and it is difficult to attract the desired actual purchase.

\subsection{High resistance of advertising audience}

A survey conducted by iResearch shows that nearly $60 \%$ of the audience of Chinese mobile Internet 
advertising are holding offensive attitude, and $36.8 \%$ of the audience are completely unwilling to accept mobile internet advertising. Meanwhile, only $32.44 \%$ mobile Internet advertising clicked by audience is valid. The proportion of audience who are unsatisfied and who don't clarify themselves both is one-third. As it can be seen from the data above, the Chinese mobile Internet advertising audience have obvious emotional resistance. This is one of the key factors leads to the non-ideal effect of advertising.

\section{THE REASON FOR THE INSUFFICIENCY OF COMMUNICATION EFFECT OF MOBILE INTERNET ADVERTISING}

\subsection{Poor credibility of advertising contents}

The fact that mobile phone users don't trust the mobile Internet advertising content is associated with the behavior of undesirable businessmen, such as disorderly using the user information without authorization. Some of the unscrupulous businessmen cheat users' tariffs, which also enhances the resentment of mobile phone users for mobile Internet advertising. The virus of the junk mails is serious. According to $\mathrm{CMCC}$, in our country, the average number of junk mails of the desktop Internet is more than normal ones and short junk message has become a focus of complaints.

\subsection{Failing to achieve accurate delivery}

Nowadays, the five mass media have tried their best to improve the advertising target, but the characteristic of the mobile Internet enables it to have more significant advantages in accurate delivery. Actually, to achieve accurate delivery, we should obtain information of Internet users as much as possible. Mobile Internet advertising can determine the scope of income, hobby, age, sex, occupation, position, or even the latest consumer behavior and so on. Through observing the behavior of Internet users or information inputs of those Internet users who participate in activities. Thus, they can deliver relevant ads anytime and anywhere on the basis of such information and the range of the delivery is flexible. Even a milk tea shop can deliver accurate advertising around a kilometer's distance. However, although the mobile Internet advertising has such a significant advantage, in fact, the necessary database to the accurate delivery isn't perfect, which leads to the fact that the accuracy of the mobile Internet advertising hasn't been well reflected.

\subsection{Insufficient humanized forms of advertising}

In this era of respect for freedom and individuality, the acceptance of forms of advertising is quite diverse. Among the five mass media, only desktop and mobile Internet can enable the audience to choose the way to accept advertising on their own. For example, mobile games now have pop-up ads which have a strong impact on the emotion of audience. According to the statistics of DCCI, $40.85 \%$ of the viewing audiences are willing to watch mobile Internet advertising especially in spare time. Thus, we can make this part of audience win points which are useful in the games by watching ads. However, so far, almost no mobile Internet advertising companies has succeeded in letting the audience choose to accept the forms of advertising.

\section{HOW TO IMPROVE THE EFFECT OF CHINA'S MOBILE INTERNET THE COMMUNICATION EFFECT OF AD}

As explained above, there are many factors that result in an ideal communication effect of mobile Internet advertising, some of which may change over time and will be resolved by themselves. And what we need to focus on is how to improve the clickthrough rate and the influence of advertising on mobile Internet traffic and how to establish a standard for mobile Internet advertising evaluation system.

\subsection{Assure that the entries on mobile Internet are neat and proper}

First, we need to integrate the existing entries. There exist too many App stores nowadays, which has resulted in the deep brutal competition between most stores and caused large quantities of loss. If the App stores can be properly integrated, we can improve the efficiency and reduce the waste of resources even if the mobile Internet advertising platforms fail to dock with the producers directly. Meanwhile, as the mobile App develops rapidly, part of the mobile Internet users would like to surf through App rather than browser. Current situation shows that both the App and the browser have their own advantages. We estimated that APP+WEB model with App and Web combined will become the mainstream in the near future. Secondly, we should explore appropriate entrance for advertising. The ads on qualified mobile applications with themes like game, lifestyle and reading are more likely to attract attention. In the field of mobile Internet advertising, although the price of mobile search advertising is higher than mobile display advertising, the cost of the mobile search advertising per thousand people was significantly lower than mobile display advertising, which means search advertising shows better effect 
and higher cost performance than the average mobile display advertising. Finally, you can also design specific mobile applications according to different ads. As the mobile users have scattered preference, different mobile applications can only attract different types of users.

\subsection{Pay high attention to the mobile Internet advertising introduction in rural marke}

Mobile Internet advertising operators should pay more attention to the advertising introduction those targets on the users in rural market. In recent years, the rural economy develops rapidly, farmers' income grows fast, and the number of mobile users in rural areas is growing faster than the big cities. At the same time, while there are a smaller proportion of mobile phone users in rural areas, there exists a higher ratio of mobile net citizens. Because despite of the high price of mobile phone, the wireless network infrastructure in rural area is better than those wired broadband network and other networks in urban area. When the price of a smart phone dropped to a few hundred dollars, low-end smart machine has quickly covered the rural market and the rural mobile Internet advertising market will certainly expand rapidly.

\subsection{Continue to spread and optimized the SoLoMo mode}

APP with mobile Internet communication, entertainment and other social attributes concerned the users most, and mobile information dissemination and social sharing (SMS / community / forums / Twitter / e-mail) has become a trend. Mobile Internet SOLOMO (social, local \& mobile) mode allows all those direct audience of the advertisement to be your salesmen for free. They will accurately propagate the ad to friends, discuss the commodity performance comprehensively and thoroughly. In this form, they will basically not provoke the resentment of indirect audience of ad.

\section{INCREASE ADVERTISING INFLUENCE ON AUDIENCE}

\subsection{Accurate delivery}

The core competitiveness of mobile internet is accurate delivery. It's far from enough. If only put advertising based on different web content or different mobile applications to deliver ads, To fully develop the potential of mobile Internet advertising, it needs to implement multiple directional which is to integrate the informations of Internet users as much as possible by observing their behavior or by the information recorded by Internet users while participating in activities. Collecting information is an ongoing but constantly changing process. Since people are constantly changing, we need to consider all aspects of the old data of the advertising audience, but also estimate the data tendency, continually modify the data, meticulously research audience characteristics, and finally deliver ads personally.

\subsection{To improve the way of advertising display}

Common display of the mobile Internet advertising is push button ads, mailing lists, banner advertising, interactive game ads, E-mail ads, wallpaper, inset advertising, competition and promotion advertising, etc. Each impressive degree of different types of advertising and the extent of adverse effects differ from that of another. Through the questionnaire survey, the author gets the result that banner ads have the best advertising effect as well as the a few negative effects of Internet users' online behavior, which is the ideal of the mobile Internet advertising display. In addition, the more time the audience surfs the Internet every day, the lower impact sensitivity for mobile Internet advertising they have. So for long-time mobile Internet users, the relatively impressive advertisement type can be used, without too much worry about the audience antipathy towards advertising.

The development of American mobile Internet advertising gives us a lot of enlightenment. Such as embedded advertisement has solved the dilemma that whether the developers charge for network application resources they provide. And the form of interactive advertising especially deserves our reference and study. Interactive advertising is often taken by desktop Internet. It also can be used on mobile Internet advertising. But the interactivity on mobile Internet advertising is stronger than it on the general desktop Internet advertising. It mainly thanks to the portability of mobile Internet equipment, which users can scan qr code and other interactive behavior anytime and anywhere. Well-designed games, promotion or other interactive activities can attract users to participate in the mobile Internet marketing anywhere and anytime. Therefore, interactive process ought to be fully used to vividly convey the company's culture, the characteristic of the brand and the features of different goods, such as using AR technology (Augmented Reality Technique) to increase AR interactions (such as their own design products, using software to form vivid visual, listening, force, touch and move feeling, and virtual trial, etc.). Though this kind of experiential advertising is relatively rare at present, its effect is very good, worthy a try.

\subsection{Emphasize feedback}

Now, the mobile Internet interaction is no longer a one-dimensional man-machine dialogue, but a two- 
dimensional communication among people, regions and the system. In order to optimize marketing mode, communicating with consumers should be more emphasized. Consumers would be able to voice their opinions or couple back the effect of advertising dissemination whenever and wherever possible. Moreover, we can provide some resources available freely to the users, and then communicate with them via the text link, audio, image or video. In this way, advertisers can know about advertising dissemination effect always and everywhere to take improvement measures or make further decisions as soon as possible.

\section{COMPLETE METHODS OF MOBILE INTERNET ADVERTISEMENT EVALUATING AND BILLING}

\subsection{Evaluation methods}

There are probably several reasons for using the weighted average of multiple factors to evaluate advertising spread effect: First, the phone's small screen can cause a lot of miss points. So, although it is the most popular and easiest way to evaluate the ad by counting the click volume among desktop Internet, it does not fit the mobile internet. Furthermore, the different ways of mobile Internet advertising has different characteristics, some have higher click rate, some has larger page views, some has higher conversion rates and some has a large amount of direct sales. Therefore, only by observing a single factor is insufficient to assess the pros and cons of mobile Internet advertising. As far as I concerned, clicking volume, page views, conversion rates, and direct sales should be given $25 \%$ to each on weighting to arrive at a composite index. It can generate a rank of mobile Internet advertising operator which can not only stimulate whom to explore new ways to improve their advertising dissemination, but provide reference to advertisers to find partners as well.

\subsection{Charge model}

While lacking a way to evaluate, it is difficult to set a good charge model. But, only to know how to evaluate is far to enough. It is because that the weighted evaluation of multiple factors is a general effect, however, different advertising operators have different strengths which makes them suitable for operating different ads. Therefore, I propose to establish a unified mobile Internet ad auction trading market, advertising operators and advertisers can participate in this market via a wired or wireless.
This approach can achieve first-degree price discrimination, through the invisible hand of the market, you can easily adopt demand pricing, competitive pricing or cost pricing. Furthermore, because the future mobile Internet advertising could become extremely popular and will take a sizable market share, the use of virtual market auction can effectively reduce the transaction costs in negotiations and procession of obtaining information. Finally, the auction must be transparent and fair which to ensure that the interests of both advertisers and operators are not infringed.

\section{CONCLUSIONS}

Mobile Internet advertising is on the rise stage of development today. In order to improve the communication effect of mobile Internet advertisement, the views of those advertisements should be increased, and the ad impression in the minds of consumers should be deepen. Meanwhile the development of rural mobile Internet advertising channels should be accelerated, SOLOMO model must be promoted, and the show mode of mobile Internet ad, focus and establish brand influence and reward the audience feedback ought to be improved. Finally, in order to make the development of the Internet industry orderly, billing methods and evaluation methods should be improved as soon as possible.

\section{ACKNOWLEDGEMENTS}

The research work was supported by breeding project communication university of China under Grant No. CUC14A21 and Humanities and Social Science Youth Foundation of Ministry of Education under Grant No. 12YJC860009.

\section{REFERENCES}

[1] China mobile Internet blue book [DB/OL]. 2012.

[2] DCCI (Data Center of China Internet). 2012

[3] XIE Tiandi. Current situation of mobile Internet advertisement: What it is and why?[J/OL]. http://www.leiphone.com/1106-s-mobi le-ad-report.html

[4] DUAN Q.S. The explosive growth of mobile Internet advertisement that would occur in 2-3 years [J/OL] http://mi.itxinwen.com/app/2012/1107/456605.html

[5] LI W.J. 2012. The current situation of Chinese mobile Internet advertisement transmission and research to its market strategy. zhejiang: Zhejiang University, 2012. 